FACULDADE DE CIÊNCIAS ECONô MICAS dA UFRGS
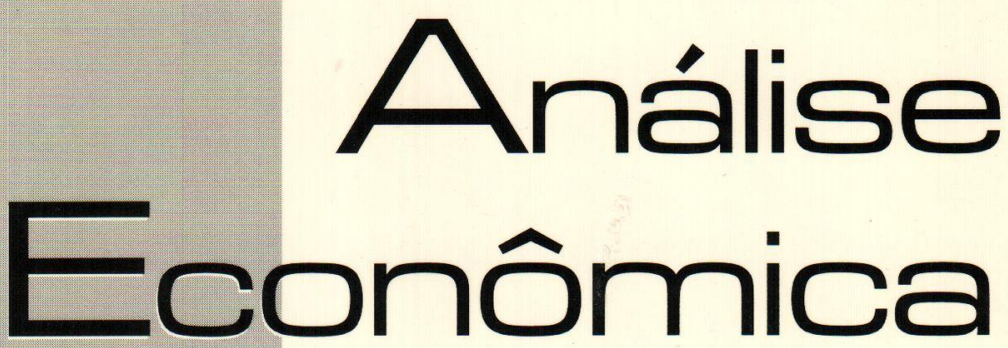

ESCOLHA DE PORTFÓLIO, INVESTIMENTO E NĀO. NEUTRALIDADE DA MOEDA

JOSÉ LUIS OREIRO

REFORMAS NA AROUITETURA FINANCEIRA INTERNACIONAL: NOVIDADES NO FRONT? ANDRÉ MOREIRA CUNHA

MERCOSUR'S CHANGE IN TRADE PATTERNS ANDRÉ FILIPE ZAGO DE AZEVEDO

O IMPACTO DA COMPOSICÃO SETORIAL, DOS FLUXOS INTRA-SETORIAIS E DA ABERTURA COMERCIAL NA PARTICIPAÇÁO DE MERCADO DAS EXPORTAÇÓES BRASILEIRAS

CLÉSIO LOURENÇO XAVIER E EMERSON FERNANDES MARÇAL

O EFEITO BALASSA-SAMUELSON E A PARIDADE DO PODER DE COMPRA NA ECONOMIA BRASILEIRA CLÁUDIO ROBERTO FÓFFANO VASCONCELOS

CICLOS Y FLUCTUACIONES FINANCIERAS: LA IRREGULAR DINÁMICA ECONÓMICA

SARY LEVY-CARCIENTE

O PENSAMENTO DE KARL POPPER: AS DIFERENTES INTERPRETACÓES DOS METODÓLOCOS DA CIENCIA ECONÓMICA

SOLANCE REGINA MARIN E RAMÓN GARCÍA FERNÁNDEZ

A EXPANSÃO DO ESCOPO TEMÁTICO DAS NEGOCIAÇÓES COLETIVAS DE TRABALHO CARLOS HENRIQUE HORN

EFEITOS DO CAPITAL SOCIAL E DO CAPITAL POLITICO NO DESENVOLVIMENTO ECONOMMICO SIMULAÇOES PARA PAISES E ESTADOS BRASILEIROS

RONALDO A. ARRAES, RICARDO CANDÉA S. BARRETO E VLADIMIR KÜHL TELES

O PROBLEMA DE RISCO MORAL NO MERCADO BRASILEIRO DE ASSISTÊNCIA MÉDICA SUPLEMENTAR LUCIANA PINTO DE ANDRADEE SABINO DA SILVA PÓRTO JÚNIOR

ANO

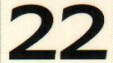

No 41

Março, 2004 
Universidade Federal do Rio Grande do Sul

Reitora: Profo. Wrana Maria Panizzi

Faculdade de Ciencias ECONOMICAS

Diretora: Prof Pedro César Dutra Fonseca

Centro de Estudos e Pesquisas Economicas

Diretor: Prof. Gentil Corazza

Departamento de Ciencias Económicas

Chefe: Prof. Ricardo Dathein

Curso de Pós-Graduação em Economia

Coordenador: Prof. Eduardo Pontual Ribeiro

Programa de Pó-Graduação em Desenvolvimento Rural

Coordenador: Prof. Jalcione Almeida

CONSElHo EDITORIAL:

Carlos G. A. Mielitz Netto (UFRGS), Eduardo A. Maldonado Filho (UFRGS), Eduardo P. Ribeiro (UFRGS), Eleutério F. S. Prado (USP), Eugênio Lagemann (UFRGS), Fernando Cardim de Carvalho (UFRJ), Fernando Ferrari Filho (UFRGS), Fernando de Holanda Barbosa (FGV/RJ), Flávio Vasconcellos Comim (UFRGS), Gentil Corazza (UFRGS), Giácomo Balbinotto Netto (UFRGS), Gustavo Franco (PUC/RJ), Jan A. Kregel (UNCTAD), João Rógério Sanson (UFSC), Joaquim Pinto de Andrade (UnB), Jorge Paulo Araújo (UFRGS), Juan H. Moldau (USP), Marcelo S. Portugal (UFRGS), Maria Alice Lahorgue (UFRGS), Paul Davidson (University of Tennessee), Paulo D. Waquil (UFRGS), Pedro C. D. Fonseca (UFRGS), Philip Arestis (Levy Economics Institut of Bard College), Roberto C. de Moraes (UFRGS), Ronald Otto Hillbrecht (UFRGS), Sabino da Silva Porto Jr. (UFRGS), Stefano Florissi (UFRGS) e Werner Baer (University of Illinois at Urbana-Champaign).

COMISSĀO EDITORIAL:

Eduardo Augusto Maldonado Filho, Fernando Ferrari Filho, Gentil Corazza, Marcelo Savino Portugal, Paulo Dabdab Waquil e Roberto Camps Moraes.

EDITOR: Prof. Fernando Ferrari Filho

Editor Adjunto: Prof. Gentil Corazza

SeCretária: Paulo Roberto Eckert

REVISÃO DE TEXTOS: Vanete Ricacheski

EdITORAÇÃo Eletrónca: Vanessa Hoffmann de Quadros

Fundador: Prof. Antônio Carlos Santos Rosa

Os materiais publicados na revista Análise Econômica são da exclusiva responsabilidade dos autores. É permitida a reprodução total ou parcial dos trabalhos, desde que seja citada a fonte. Aceita-se permuta com revistas congêneres. Aceitam-se, também, livros para divulgação, elaboração de resenhas e recensões. Toda correspondência, material para publicaçāo (vide normas na terceira capa), assinaturas e permutas devem ser dirigidos ao seguinte destinatário:

PROF. FERNANDO FERRARI FILHO Revista Análise Econômica - Av. João Pessoa, 52 CEP 90040-000 PORTO ALEGRE - RS, BRASIL Telefones: (051) 316-3513 - Fax: (051) 316-3990

Análise Econômica E-mail: rae@ufrgs.br

Ano 22, $n^{\circ} 41$, março, 2004 . Porto Alegre

Faculdade de Ciências Econômicas, UFRGS, 2004

Periodicidade semestral, março e setembro.

Tiragem: 500 exemplares

1. Teoria Econômica - Desenvolvimento Regional -

Economia Agrícola - Pesquisa Teórica e Aplicada -

Periódicos. I. Brasil

Faculdade de Ciências Econômicas,

Universidade Federal do Rio Grande do Sul. 


\title{
O problema de risco moral no mercado brasileiro de assistên- cia médica suplementar
}

\author{
Luciana Pinto de Andrade \\ Sabino da Silva Pôrto Júnior ${ }^{2}$
}

\begin{abstract}
Resumo:A assistência médica suplementar no Brasil teve uma forte expansão nos últimos dez anos e hoje atende a mais de $25 \%$ da população. Recentemente este setor foi alvo de importantes modificações no que diz respeito a sua regulamentação. O estudo das relações que existem entre os agentes que fazem parte deste mercado e as falhas de informação que surgem nestas relações é fundamental para se compreender o funcionamento da assistência médica suplementar neste ambiente.

$O$ objetivo deste trabalho é identificar como o problema de risco moral tem afetado o funcionamento do mercado brasileiro de assistência médica suplementar, antes e após o processo de regulamentação vivenciado pelo setor, destacando o comportamento das operadoras e seguradoras e a sua influência para os consumidores. A partir do estudo realizado, a principal constatação foi a de que as operadoras de planos e seguros de saúde estão utilizando diversos mecanismos de compartilhamento de risco, buscando inibir a sobreutilização dos serviços prestados, mesmo que isto acabe onerando os consumidores.
\end{abstract}

Palavras-chave: Assistência médica suplementar; Moral Hazard; Planos e seguros de Saüde.

\begin{abstract}
Supplemental medical assistance in Brasil has expanded greatly over the last tem years. Today it serves, more than $25 \%$ of the population. To study the relationships that exist between the client and suppliers that make up this market and the lack of information which comes from these relationships, it is fundamental to understand this type of assistance, with this, we can define the role of each one within this particular market. Looking for adequate health assistance, which avoids over burdening any of the components. The aim of this wrote is to identify how the risk of moral hazard has effected the supplementary medical assistance market, hoe the operators and insurers are behaving and in what way this
\end{abstract}

\footnotetext{
- Os autores agradecemos comentários feitos pelo parecerista anônimo e esclarecem que eventuais erros contidos no presente artigo são de responsabilidade dos autores.

${ }^{1}$ Mestranda em Administração de Empresas do IAG/PUC-RIO.

2 Professor do PPGE/UFRGS.
} 
behaviour has effected the client. The principal conclusion of this study was the verification that health insurance operators are using every means to compartmentalise risk, principally diminishing the over use of services. However, using these means moved more of the onus onto the consumer. Consequently, many are abandoning health insurance programmes and relying on the public health system.

Key words: Supplementary Medical Assistance, Moral Hazard, Health Insurance Plans.

JEL Classification: I1 1 - Analysis of Health Care Markets

\section{Introdução}

O mercado de seguros tem sido um dos principais focos da teoria da informação assimétrica, desde o início da década de 1960. Os problemas de seleção adversa e de risco moral são abordados, a fim de se propor soluções que possam, no mínimo, amenizar a incidência dessas assimetrias de informação entre os agentes envolvidos.

A seleção adversa é um problema de informação assimétrica que acontece antes da aquisição do seguro. Especificamente no caso do seguro-saúde, a assimetria ocorre porque a seguradora tem dificuldades em verificar qual o grau de risco do indivíduo que deseja contratar o seguro. Em função disso, não pode diferenciar seu preço de acordo com a probabilidade de adoecer do agente. Atualmente, no Brasil, este problema de seleção adversa tem sido combatido via menu de contratos, já que existe uma diversidade maior de seguros, os quais oferecem diferentes tipos de coberturas assistenciais. Além disso, as seguradoras têm exigido que se faça uma declaração de saúde, na qual o indivíduo esclarece qual a sua condição de saúde, para que seja verificado o seu perfil de risco.

Já o problema de risco moral, que ocorre após a aquisição do seguro pelo agente, se caracteriza pela sobreutilização dos serviços disponibilizados, pois o indivíduo está totalmente protegido de qualquer despesa. Para este problema também foram propostas algumas soluções, mas que, diferentemente da seleção adversa, dificilmente conseguem eliminar totalmente esta falha de informação.

Diante disso, analisar os problemas de assimetria de informação, principalmente no que se refere ao risco moral, em mercados como o da assistência à saúde, tem sido cada vez mais alvo de pes- 
quisas. No Brasil, o interesse por estudos nesse campo vem aumentando, devido ao fato da assistência suplementar ter uma presença significativa no sistema de atendimento à saúde. Estudar as relações existentes entre os agentes que compōem este segmento de mercado (consumidores, operadoras, seguradoras, prestadores de serviços e governo), bem como as falhas de informação que surgem nestas relaçōes, é de fundamental importância para a compreensão do funcionamento do mercado da assistência médica suplementar.

Dessa forma, é possível se observar os principais impactos da assimetria de informação para o bem-estar dos agentes envolvidos. Além disso, se pode definir o papel de cada um neste mercado, como uma das formas de se obter uma assistência à saúde adequada, que evite onerar, de forma excessiva, qualquer um dos agentes.

Este trabalho se propõe a fazer um levantamento das principais soluções propostas por diversos autores ao problema de risco moral. A partir disso, pretende-se verificar quais dessas soluções têm sido utilizadas pelas operadoras de planos e seguros de saúde, no Brasil, antes e depois da regulamentação do setor ${ }^{3}$, ocorrida em 1998, e como esses mecanismos têm afetado os seus consumidores.

O setor da saúde foi escolhido pois, no Brasil, o mercado de assistência médica suplementar ${ }^{4}$ é responsável pela assistência de $25 \%^{5}$ de toda a população. Além disso, a regulamentação estabelecida reforçou a sua importância e afetou decisivamente tanto o comportamento das operadoras quanto a sua relação com os seus usuários.

Na primeira seção, serão apresentadas algumas visões sobre o problema de risco moral, destacando quais são as suas principais conseqüências e soluções possíveis. Na seção seguinte, é feita uma análise do processo de regulamentação dos planos e seguros de saúde iniciado em 1998. Por fim, na última seção, serão analisados, à luz da teoria de risco moral, os contratos de algumas das principais ope-

\footnotetext{
${ }^{3}$ A assistência médica suplementar foi regulamentada somente em junho de 1998, com a aprovação da Lei dos Planos e Seguros de Saúde n 9.656 . Esta legislação será apresentada de forma mais detalhada em seção posterior.

${ }_{4}^{4}$ Neste trabalho, conforme Almeida (1998), adota-se o termo Assistência Suplementar à Saúde, o qual compreende as várias modalidades de assistência médica prestada tanto por empresas a seus funcionários, quanto aquela disponibilizada às famílias através de planos ou seguros de saúde. A autora baseia-se em trabalho realizado por Médici (1991), no qual o Setor Privado de Assistência à Saúde é composto, além destas modalidades de assistência médica suplementar, de segmentos beneficentes filantrópicos, e de clínicas e hospitais privados que prestam serviços ao setor público.

${ }^{5} \mathrm{PNAD} / 98$.
} 
radoras de planos e seguros de saúde brasileiras e suas alterações após a aprovação da nova legislação que regulamentou o setor.

\section{Aspectos teóricos sobre o risco moral no mercado de assistência suplementar à saúde}

O propósito desta seção é apresentar algumas abordagens teóricas sobre o problema de risco moral no mercado de seguro, destacando os mecanismos propostos para solucionar esse problema de informação assimétrica.

O risco moral surge porque, ao contratar um seguro, o indivíduo (agente) estará totalmente coberto contra qualquer doença, e como a seguradora (principal) não dispõe de mecanismos para monitorar as precauções tomadas por ele com relação a sua saúde, este agente terá incentivos a sobreutilizar a assistência médica que lhe é disponibilizada. Em outras palavras, "o indivíduo irá usar mais os serviços do que no caso em que estivesse tendo que pagar por toda a assistência médica fornecida"(CUTLER E ZECKHAUSER, 2000, p. 576).

De posse de um seguro total, quanto menos cuidado o indivíduo tomar, maiores serão as chances de ele adoecer e da seguradora precisar incorrer em despesas extras. Esse desincentivo à precaução acaba por criar o problema de risco moral(KATZ, 1991). A assimetria de informação está justamente no fato de que a precaução tomada pelo agente, após adquirir o seguro, se tornará uma informação privada, já que a seguradora não será capaz de monitorar suas atitudes(PRESCOTT, 1999).

Para Shavell (1979), o caráter de proteção que um seguro oferece a um indivíduo acaba por fazer com que este empreenda menos esforços para evitar que ocorram perdas e isto provocaria o problema de risco moral. Deve-se observar que a presença de risco moral não faz com que o seguro deixe de ser ofertado. Entretanto, é necessário que se introduza algum mecanismo que possa reduzir este problema. $\mathrm{O}$ autor sugere que o seguro oferecido tenha uma cobertura parcial. Caso contrário (uma cobertura total), seria necessário que os cuidados tomados pelo indivíduo fossem monitorados, o que, além de mais caro, pode ser impossível de ser praticado. Assim, ao oferecer um menu de contratos, a seguradora conseguirá obter (via auto-seleção) mais informações sobre o esta- 
do de saúde e o comportamento preventivo do indivíduo, antes da assinatura do contrato.

Arnott e Stiglitz (1991) também afirmam que "quanto mais abrangente for a cobertura do seguro, menor será a precaução tomada pelo indivíduo, quanto a sua saúde". Os autores propõem que a limitação da cobertura é uma das formas disponíveis para a diminuição do problema. Outra solução, seria a imposição de exclusividade na provisão, ou seja, tentar fazer com que os indivíduos adquiram um seguro de uma única seguradora.

A principal conclusão dos autores é a de que, no mercado de seguros, o controle da abrangência da cobertura da apólice é um mecanismo importante de monitoramento das ações do indivíduo, mas que não é capaz de eliminar o problema de perigo moral. Isto porque cada firma só poderá controlar a sua venda para cada agente, sem poder ter informação sobre os demais seguros adquiridos em outras firmas por cada indivíduo. Mesmo que, no caso do seguro saúde, se possa restringir a compra de apólices de outras operadoras, não se tem controle sobre o seguro oferecido pelo empregador ou até mesmo sobre seguros implícitos fornecidos por familiares e amigos.

De maneira geral, os autores que tratam sobre o problema de risco moral têm a mesma opinião sobre as principais medidas que devem ser adotadas para se tentar diminuir a incidência dessa assimetria de informação. A principal delas é fazer com que os segurados compartilhem o risco, ou parte dele, que antes era assumido apenas pela seguradora. Ou seja, deve-se, do ponto de vista da seguradora, exigir que os consumidores paguem uma parcela do valor cobrado por consultas, exames, etc. Este tipo de contribuição é chamada de co-participação ou co-seguro. Deste modo, a seguradora deixa de ser responsável por $100 \%$ das despesas do segurado. Outra forma de requerer a participação do consumidor é por meio de deduções no seguro, ou seja, o agente paga as despesas iniciais, como uma franquia, e o que ultrapassar este limite fica a cargo da seguradora.

Essas seriam algumas formas de compartilhamento de risco entre a seguradora e o segurado, visando reduzir o problema de risco moral. Monitorar o comportamento do indivíduo e suas precauçōes seria o ideal (first best) para a seguradora, pois solucionaria o problema de falha informacional. Porém, isso seria muito dispendioso ou, até mesmo, inviável. Assim, a solução reside em utilizar mecanismos como cobertura parcial, co-pagamentos e deduções, como 
uma forma de se observar uma variável que está relacionada com as ações tomadas pelo indivíduo, ou seja, uma maneira de verificar o resultado das ações e precauções do agente(SALANIÉ, 1997).

O problema de risco moral estará presente também na relação entre os provedores de serviços (médicos, laboratórios, clínicas, hospitais, etc.) e as operadoras de planos e seguros de saúde. Como tais provedores são pagos de acordo com a quantidade de serviços prestados, acabam tendo incentivos a demandar um maior volume de serviços, já que não existe um controle rígido sobre esta demanda. Este tipo de situação também gera o problema de risco moral.

O que ocorre, na verdade, é que o paciente possui uma relação de confiança com o médico, pois este é o responsável pelo tratamento e quem irá determinar a quantidade demandada de serviços. Entretanto, é preciso fazer uma ressalva. Algumas vezes, um tratamento prolongado pode não significar que esteja ocorrendo o problema de risco moral, mas, sim, que o médico esteja procurando obter um diagnóstico o mais preciso possível.

No Brasil, ainda não foram implementados mecanismos de controle para se reduzir a incidência desta situação de risco moral. Seria importante, por exemplo, a introdução de instrumentos em que os provedores dos serviços compartilhassem também o risco que, até então, é assumido somente pelas seguradoras. Uma outra solução possível seria a mudança na forma com que os provedores são reembolsados pelas seguradoras, de forma que não estivesse baseada apenas no volume de serviços prestados. Os demais aspectos referentes ao funcionamento da assistência médica suplementar no Brasil serão abordados na próxima seção.

\section{Regulamentação dos planos e seguros de saúde no Brasil}

O Sistema de Saúde brasileiro passou por profundas transformações desde o início de 1980. Estas mudanças foram observadas tanto na assistência à saúde prestada pelo setor público quanto na prestação de serviços oferecida pela medicina suplementar. $\mathrm{Na}$ esfera pública, o governo federal vem buscando descentralizar essa assistência, transferindo uma responsabilidade maior no provimento desses serviços para os municípios.

Já o sistema de assistência médica suplementar sofreu uma forte expansão na década de 1990 e, após dez anos, atende a mais de 
$25 \%$ da população brasileira. Até o momento, as operadoras de planos e seguros de saúde encontram-se divididas em cinco modalidades, quais sejam:

- Medicina de Grupo: empresas que prestam serviços médicos, por meio de infra-estrutura própria ou credenciada, e utilizam o prépagamento como forma de financiamento. Ofertam planos de saúde empresariais e familiares. A entidade que as representam é a Associação Brasileira de Medicina de Grupo (ABRAMGE).

- Autogestão: são aquelas empresas ou entidades públicas que fornecem planos de saúde aos seus funcionários, os quais contribuem mensalmente para ter este direito. O Comitê de Integração de Entidades Fechadas de Assistência à Saúde (CIEFAS) é o representante das empresas e associações públicas, as quais correspondem a uma modalidade de medicina suplementar. Já a Associação Brasileira das Autogestões em Saúde Patrocinadas pelas Empresas (ABRASPE) representa tanto as empresas privadas quanto algumas entidades públicas, e caracterizam-se como uma outra modalidade. Atualmente, verifica-se o início do processo de unificação entre estas duas entidades.

- Cooperativas Médicas: são administradas pelos próprios médicos e comercializam planos individuais e empresariais. O sistema de pré-pagamento é utilizado, aliado ao de co-pagamento. Estas cooperativas prestam seus serviços através da sua rede própria e por meio de serviços credenciados. Tais cooperativas são conhecidas como Unimeds e representadas pela Confederação das Unimeds.

- Seguros de Saúde: Nesta modalidade as seguradoras reembolsam todas as despesas médicas do segurado, de acordo com as especificidades da apólice de seguro. O segurado paga um valor mensal, de acordo com o prêmio estipulado na apólice, e pode optar pelos médicos e hospitais que desejar.

Até 1998, os planos e seguros de saúde não possuíam uma legislação específica. Qualquer discussão ou reclamação sobre este tipo de assistência tinha amparo somente no Código de Defesa do Consumidor.

Em junho de 1998 foi aprovada a Lei n. ${ }^{\circ} 9.656^{6}$, que propunha a regulamentação do sistema de medicina suplementar brasileiro.

- Todas as informações referentes a esta Lei foram obtidas no site: www.ans.gov.br 
Um dos principais objetivos da regulamentação foi estabelecer a responsabilidade de cada agente que participa desse mercado, seja o consumidor, a operadora ou seguradora, ou a empresa que presta o serviço. A falha de regulamentação existente levava cada operadora a estipular suas próprias regras. Em conseqüência, ocorriam abusos, tais como: reajustes elevados, exclusōes de coberturas para certas doenças, cancelamentos unilaterais de contratos, etc.

Segundo a Agência Nacional de Saúde Suplementar ${ }^{7}$, os objetivos da regulamentação eram: assegurar, aos usuários do sistema, cobertura assistencial integral e regular as condições de acesso; definir e controlar as condições de ingresso, operação e saída das empresas e entidades que operam no setor; definir e implantar mecanismos de garantias assistenciais e financeiras que assegurem a continuidade da prestação de serviços de assistência à saúde contratados pelos consumidores; dar transparência e garantir a integração do setor de saúde suplementar ao SUS e o ressarcimento dos gastos gerados por usuários de planos privados de assistência à saúde no sistema público; estabelecer mecanismos de controle da abusividade de preços; e definir o sistema de regulamentação, normatização e fiscalização do setor privado de saúde.

Foram adotadas medidas que alteraram significativamente a conduta das operadoras, e o processo de adaptação a essas regras ainda não chegou ao fim.

As medidas foram significativas porque modificaram desde a oferta dos planos até os parâmetros para os preços que devem ser cobrados. Por exemplo, foram criadas algumas categorias de planos e somente estas podem ser ofertadas, seja separadamente ou não. As operadoras foram proibidas de limitar tanto o número de consultas quanto o de internações hospitalares. Foram estabelecidas faixas etárias em que cada usuário deveria estar inserido e limites para os preços dos planos de acordo com estas faixas. Enfim, estas são algumas das mudanças realizadas por meio da regulamentação dos planos e seguros de saúde e que serão detalhadas logo a seguir, a fim de se verificar qual o impacto desta nova legislação para consumidores, operadoras e prestadores de serviços.

7 "Regulação dos Planos Privados de Assistência à Saúde pela ANS: avaliação, perspectivas e interface SUS-Saúde Suplementar". Agência Nacional de Saúde, junho de 2001. A criação desta Agência e suas atribuiçōes serāo expostas logo a seguir. 
Inicialmente, o poder de regulação foi delegado ao Conselho de Saúde Suplementar (CONSU), presidido pelo Ministro da Saúde. Porém, em janeiro de 2000, foi sancionada a Lei n. ${ }^{\circ} 9.961 / 00$, que criou a Agência Nacional de Saúde Suplementar (ANS), ficando esta responsável pela grande maioria das atribuiçōes antes conferidas ao CONSU. Foi estabelecido que a ANS seria o órgão responsável pela regulamentação, normatização e fiscalização de todas as atividades relacionadas à assistência médica suplementar.

Tanto o CONSU quanto a ANS estipularam resoluções que dispõem de assuntos relativos tanto às operadoras de planos e seguros de saúde, quanto concernentes ao próprio funcionamento e atribuições da agência e do conselho. As outras modificaçōes na Lei n. ${ }^{\circ} 9.656$ ocorreram por meio de 45 Medidas Provisórias, sendo a última decretada em agosto de 2001 (ressalva-se que, destas Medidas Provisórias, muitas foram reedições) ${ }^{8}$.

Uma das primeiras modificaçōes propostas pela Lei n. ${ }^{\circ} 9.656$ foi o estabelecimento de alguns tipos de planos, chamados "planos mínimos", visando atender necessidades específicas. Foram criadas as seguintes categorias: o plano ambulatorial, que oferece consultas médicas, exames e demais procedimentos que estejam enquadrados no âmbito de ambulatório; o plano hospitalar, que oferece o atendimento hospitalar e todas as necessidades decorrentes desta internação; o plano hospitalar com obstetrícia, destinado às mulheres, que oferece, além da cobertura do plano hospitalar, consultas, exames e demais procedimentos até o recém-nascido completar 30 dias de vida; e o plano odontológico, que compreende consultas, exames e outros tratamentos realizados em consultório.

Instituiu-se também o plano de referência, que compreende o plano ambulatorial e o plano hospitalar com obstetrícia, sendo que todas as operadoras devem estar disponibilizando este tipo de plano ${ }^{9}$ para seus clientes, desde o dia 3 de dezembro de 1999 (exclui-se desta obrigatoriedade as operadoras de autogestão e aquelas que oferecem somente o plano odontológico).

\footnotetext{
${ }^{8} \mathrm{~A}$ análise feita nesta seção abordará a Lei com todas as modificaçōes feitas pelas Medidas Provisórias e Resoluções até abril de 2002.

O plano referência não inclui nem tratamento clínico ou cirúrgico experimental, nem o fornecimento de próteses, órteses e seus acessórios não ligados ao ato cirúrgico.
} 
Outra mudança que alterou a conduta antes adotada pelas operadoras foi a decisão de que não poderiam deixar de cobrir doenças e lesões preexistentes ${ }^{10}$. Isto só poderá ocorrer șe a operadora, durante os 24 meses após o contrato ter sido assinado, conseguir provar que o paciente já era portador da doença e que este tinha conhecimento de tal fato.

$\mathrm{Na}$ verdade, antes da regulamentação, as operadoras acabavam excluindo diversas doenças, por considerá-las preexistentes e, assim, traziam prejuízos aos consumidores que, muitas vezes, eram surpreendidos com interrupçōes de seus tratamentos. Com a regulamentação, acredita-se que esteja mais difícil para as operadoras alegarem a preexistência de alguma doença, pois agora o ônus da prova cabe a elas.

Buscando evitar problemas e conflitos, o CONSU determinou que o consumidor deve ser examinado, antes da assinatura do contrato, por um médico credenciado, que investigará se o paciente possui alguma doença considerada preexistente. Caso isto não seja confirmado, o consumidor assinará uma declaração, na qual constará que não possui e desconhece qualquer doença preexistente. $\mathrm{Se}$, por outro lado, confirmar-se uma possível doença, o paciente terá de optar entre duas alternativas: ou ele espera os 24 meses para poder ser atendido e arca com as despesas durante este período, ou ele paga o chamado "agravo", ou seja, uma quantia a mais em cada mensalidade, para que possa ter a sua doença preexistente coberta pelo plano.

Novas regras aos procedimentos das operadoras, até então comuns, também foram criadas. Ficou proibida a limitação do número de consultas, de exames e dos dias de internação hospitalar, seja em Unidade de Terapia Intensiva (UTI) ou não. Antes dessa legislação, as operadoras tinham como costume limitar o número de consultas e estabelecer prazos máximos para a internação hospitalar, até em UTI. Segundo o Instituto de Defesa do Consumidor (IDEC), existiam operadoras que limitavam em três dias o prazo da internação em UTI. Muitos consumidores recorreram à justiça, mas a maioria só conseguia estender um pouco mais os prazos. Com a regulamen-

\footnotetext{
10 São aquelas que o paciente tem conhecimento de ser portador, quando da contratação da operadora.
} 
tação, passou a ser ilegal a limitação de prazos para a internação hospitalar.

Essa medida resultou em uma mudança no comportamento das operadoras, já que não tinham mais como impedir a permanência do paciente no hospital, até que o médico autorizasse sua saída. Não obstante, esta pode ser uma situação potencial para o surgimento do problema de risco moral na relação entre o provedor da assistência médica e a operadora. Os hospitais, por exemplo, recebem das operadoras o equivalente aos serviços prestados relativo ao número de dias em que o paciente ficou internado. Sendo assim, pode haver um estímulo ao prolongamento do prazo de internação, com a anuência de um médico, já que o hospital irá se beneficiar, e o consumidor não precisará incorrer em despesas em virtude disso. Já para os usuários dos planos e seguros de saúde, esta medida traz benefícios porque não ocorrerão mais interrupções nas internaçōes, a operadora deverá pagar todos os custos, e o paciente só deixará o hospital quando o médico responsável lhe autorizar.

Uma outra providência tomada foi proibir que o contrato seja rescindido de forma unilateral, o que impede o cancelamento dos contratos repentinamente. As duas exceções são para os casos em que é comprovada fraude por parte do consumidor ${ }^{11}$ ou quando ocorre falta de pagamento da mensalidade por mais de 60 dias.

Ficou estabelecido, também, que nem pessoas idosas nem portadores de deficiência física podem ser impedidos de adquirir um plano de assistência à saúde. Os idosos também sofriam outro tipo de penalização, em função dos reajustes abusivos feitos pelas operadoras. Para evitar esse problema, foram criadas sete faixas etárias, quais sejam: de zero a 17 anos; de 18 a 29 anos; de 30 a 39 anos; de 40 a 49 anos; de 50 a 59 anos; de 60 a 69 anos; e de mais de 70 anos. De acordo com a regra, o valor fixado para a última faixa não pode superar em seis vezes o valor da primeira faixa etária. Conforme Andrade (2000, p. 7), "o objetivo do governo ao propor este tipo de regulamentação é implementar um subsídio cruzado entre os indivíduos de grupos etários diferentes". Em outras palavras, como o valor do prêmio cobrado aos indivíduos mais idosos está vinculado

"São consideradas fraudes, por exemplo, o consumidor não informar que possua uma doença preexistente ou uma pessoa que não esteja coberta utilizar o plano. 
ao prêmio cobrado aos mais jovens, então cobra-se um valor maior destes últimos, a fim de cobrir o alto risco daqueles mais idosos, pois seus prêmios não condizem com o seu risco esperado.

As questões que se referem ao descredenciamento de hospitais e outros prestadores de serviços da rede credenciada também sofreram alterações. Antes da regulamentação, as operadoras podiam cancelar os contratos com a rede de atendimento credenciada sem avisar previamente seus consumidores e beneficiários. Com a Lei n. ${ }^{\circ} 9.656$, instituiu-se que o descredenciamento só pode ocorrer se o Ministério da Saúde e os consumidores forem comunicados com 30 dias de antecedência. Além disso, o prestador de serviço descredenciado deve ser substituído por outro de qualidade equivalente. Esta regra só não precisa ser cumprida se o cancelamento do contrato de credenciamento tenha ocorrido em virtude de fraude ou alguma outra infração do prestador do serviço.

Os critérios exigidos para o reembolso ao Sistema Único de Saúde (SUS), quando o consumidor for atendido pela rede pública e este possuir um plano ou seguro de saúde foram definidos. Desta forma, o SUS poderá ter todas as despesas do atendimento ressarcidas. Segundo Andrade $\mathcal{E}$ Lisboa (2001, p.307), "esta medida é fundamental para garantir que as firmas não possam realizar seleção favorável de risco na sociedade, além de garantir um sistema de financiamento mais igualitário entre os grupos sociais".

No que diz respeito à adaptação dos contratos antigos à nova legislação, isto será uma opção do consumidor, que poderá escolher entre permanecer com seu plano ou adapta-lo às novas condições, não existindo prazo máximo para tal. Assim, o consumidor poderia analisar e optar se permaneceria com o contrato antigo ou se o adaptava. Entretanto, mesmo estes contratos antigos foram submetidos a algumas regras que estavam incluídas na nova legislação. Exemplos disto são: a proibição do cancelamento do contrato pela empresa, do aumento da mensalidade sem autorização prévia, da interrupção da internação e da instituição de novas carências em virtude de atraso no pagamento. Já os contratos novos, comercializados desde 4 de janeiro de 1999, estão submetidos à nova legislação.

Resumidamente, estas foram as principais alterações propostas pela Lei $n^{\circ} 9.656$, que implementou a regulamentação dos planos e seguros de saúde. Segundo a Agência Nacional de Saúde Suple- 
mentar, ainda são necessárias algumas mudanças para que o processo de regulamentação possa ser consolidado, dentre as quais estão: concluir as regras gerais de abertura, funcionamento e saída de operadoras; introduzir um sistema eficiente de transferência de usuários de uma determinada operadora, quando esta é liquidada; e adaptar a maioria dos contratos antigos à nova regulamentação.

Na próxima seção, serão analisados os contratos elaborados por cada modalidade de assistência à saúde. O objetivo é indicar as possíveis falhas existentes nos contratos das operadoras de planos de saúde, através das quais o problema de risco moral fica evidenciado. Também serão apresentadas as soluções encontradas pelas operadoras para tentar evitar tal problema, principalmente com as mudanças trazidas pela regulamentação, e de que forma esse comportamento tem afetado os consumidores. Além de apontar estes fatos, serão propostas algumas alternativas que possam contribuir para a diminuição da incidência do risco moral.

\section{$4 O$ problema de risco moral nos contratos das operadoras de planos e seguros de saúde}

Nesta seção, será feita uma análise do problema de risco moral existente nos contratos que são disponibilizados pelas operadoras de planos e seguros de saúde. Optou-se por estudar um contrato de cada uma das cinco modalidades de assistência médica suplementar.

Antes, porém, é necessário esclarecer alguns pontos. Primeiro, não se pretende, neste trabalho, encerrar qualquer questão sobre a forma como se dá o problema de risco moral nos planos e seguros de saúde, nem sobre como as operadoras têm se protegido contra esta assimetria de informação. O que se pretende é apenas elucidar alguns casos e, assim, verificar que existem várias maneiras para se tratar com o risco moral. Inclusive porque existe muita heterogeneidade entre contratos dentro de uma mesma modalidade. Segundo, neste trabalho, não será revelado o nome da operadora que se está tratando, mas o que será destacado é a que modalidade o contrato pertence, porque o objetivo aqui não é fazer juízo de valor algum sobre os contratos das operadoras. 


\section{I Critérios utilizados para a escolha das operadoras e para a coleta dos contratos ${ }^{12}$}

Nesta seção, explicitam-se as razões pelas quais as operadoras aqui tratadas foram escolhidas. Além disso, são apresentadas as principais características de cada contrato, tais como a sua abrangência, cobertura, categoria, etc.

Como já foi apresentado, existem cinco modalidades de assistência médica suplementar. Inúmeras operadoras ou seguradoras pertencem a cada modalidade. Neste trabalho, a caracterização será feita da seguinte forma: a Operadora 1 será a representante das Cooperativas Médicas; a Operadora 2, dos Seguros de Saúde; a Operadora 3, da Medicina de Grupo; a Associação 4, do CIEFAS, que representa as empresas e associaçôes públicas que fornecem para seus funcionários e associados assistência à saúde; e a Associação 5 , da ABRASPE, que representa as empresas privadas, em sua maioria, que disponibilizam atendimento médico a seus funcionários.

Quanto à Operadora 1, esta foi escolhida por se tratar da cooperativa médica com maior representatividade e abrangência territorial e populacional no Rio Grande do Sul. Já a Operadora 2, representante das seguradoras, possui cerca de $45 \%$ do total dos prêmios de seguro-saúde ${ }^{13}$ no Brasil. A Operadora 3, que pertence à medicina de grupo, possui a maior representatividade e tradição entre os representantes atuantes no Rio Grande do Sul.

Quanto às entidades de autogestão, é importante salientar que a escolha das associações de funcionários dessas duas modalidades procurou valorizar aquelas que representavam um maior número de funcionários e, dessa forma, prestam assistência a um número maior de pessoas. Assim, optou-se por escolher como Associação 4, representante do CIEFAS, a entidade que assiste aos funcionários de um banco público. Já a Associação 5, pertencente à ABRASPE, presta assistência a funcionários federais de diversos ministérios, além de outras instituições públicas.

\footnotetext{
${ }^{12}$ A pesquisa das operadoras e dos contratos foi realizada no periodo de maio a outubro de 2001. ${ }^{13}$ Segundo dados da FENACOR (Federação Nacional dos Corretores de Seguros Privados, de Capitalizaçāo e de Previdencia Privada), até o mês de novembro de 2000. Disponível em www.fenacor.com br/ranking 1 12000.htm. Acesso em 25/05/2001
} 
Quanto aos contratos coletados, procurou-se selecionar aqueles com coberturas semelhantes e abrangentes, sendo que suas características principais são as seguintes:

- Contrato da Operadora 1: plano de saúde individual, com cobertura nacional ambulatorial e hospitalar, com obstetrícia.

- Contrato da Operadora 2: seguro de saúde individual, com cobertura nacional ambulatorial e hospitalar, com obstetrícia.

- Contrato da Operadora 3: plano de saúde empresarial, com cobertura local ambulatorial e hospitalar.

- Contrato da Associação 4: plano de saúde empresarial, com cobertura nacional ambulatorial e hospitalar, com obstetrícia.

- Contrato da Associação 5: plano de saúde empresarial, com cobertura nacional ambulatorial e hospitalar, com obstetrícia.

\subsection{Análise dos Contratos das Operadoras de Planos e Seguros de Saúde no Brasil}

Nesta seção, são analisados cinco contratos, cada um de uma modalidade de assistência médica suplementar, e são destacados os principais aspectos que originam ou podem originar o problema de risco moral, além de verificar o que as operadoras têm feito a fim de evitar a sobreutilização dos serviços que oferecem, principalmente após as mudanças impostas pela nova legislação.

$\mathrm{O}$ primeiro contrato analisado pertence à modalidade das Cooperativas Médicas e é oferecido pela Operadora 1. O que se percebe é uma constante preocupação com respeito à racionalização da assistência médica oferecida. No levantamento feito, verificou-se que têm sido implementadas, após a necessidade de adequação à nova legislação, algumas mudanças que visam combater o problema de risco moral.

Primeiramente, verificou-se que houve uma alteração nos preços cobrados dos planos de saúde que não exigem a co-participação por parte do usuário. Anteriormente à regulamentação, o preço de plano sem co-pagamento, para uma certa faixa etária, era praticamente igual ao plano que exigia a contribuição. No caso, se o usuário consultasse com um médico, uma vez ao mês, o plano sem participação já se tornava mais vantajoso do que o com co-participação. Ou seja, a diferença entre os dois planos era menor que o valor de co-participação cobrado por uma consulta realizada. 
Como conseqüência desse fato, era verificada uma demanda muito maior pelos planos que não cobravam tipo algum de participação e transferiam todas as despesas realizadas pelos usuários para a operadora. $\mathrm{O}$ que aconteceu foi que o preço do plano de saúde sem co-participação foi praticamente dobrado, e tornou-se vantajoso apenas para aquelas pessoas que consultavam médicos mais de quatro vezes por mês. E este plano deixou de ser interessante para os usuários de baixo risco, e que pouco utilizavam os serviços. Esta mudança caracteriza-se como uma nítida medida contra a sobreutilização dos serviços prestados, ou seja, uma ação contra a incidência do problema de risco moral.

Outra alteração em função da nova legislação foi quanto ao período de carência das internações hospitalares. Anteriormente, a carência para este serviço era de 60 dias, o mesmo período imposto para consultas médicas e exames. Hoje, as internações hospitalares têm carência de 120 dias. O que se percebe nesta mudança é uma forma de reduzir os possiveis gastos com essas internações durante um período de tempo maior. Ou seja, por mais tempo, a operadora não precisará arcar com certos gastos e com uma possível não racionalização dos serviços, tanto pelo usuário quanto pelo próprio hospital, postergando, assim, a sua exposição ao problema de risco moral. Entretanto, para os consumidores, este tipo de alteração não é desejável, porque implicaria pagamentos prolongados das mensalidades, contudo sem poder usufruir os serviços oferecidos.

Analisando especificamente o contrato atual da Operadora 1, percebe-se sua adequação às exigências impostas pela Lei dos Planos e Seguros de Saúde. Por exemplo, instituíram-se as sete faixas etárias, para a cobrança dos planos, e que a última não pode ultrapassar em sete vezes o valor da primeira. Mas o que se verifica é que o preço cobrado está sempre perto do limite estabelecido pela lei. Ou seja, o preço da última faixa etária costuma ficar de cinco a seis vezes mais caro que o valor cobrado para usuários que pertencem à primeira faixa etária.

O fato que mais se destaca é o alto índice de co-participação do plano. Para consultas médicas é cobrado um percentual de $40 \%$ do valor total. Esta participação é tão alta justamente para evitar ao máximo a ocorrência do problema de risco moral. Mas, do ponto de vista do consumidor, as cobranças são onerosas, na medida em 
que o valor de uma co-participação representa $20 \%$ sobre o preço de uma consulta, por exemplo, além do valor pago pela mensalidade.

O contrato analisado da Operadora 1 possui o maior percentual de co-participação, relativamente ao cobrado para planos empresariais, não havendo praticamente incentivos a uma sobreutilização dos serviços prestados, pois o ônus é muito grande.

Parti-se, agora, para a análise da Operadora 2, que oferta seguros de saúde. Observa-se que, dos contratos analisados, o valor cobrado pelo plano é o maior. Uma das explicaçōes reside no fato de que não existe co-participação para consultas médicas, exames e internações hospitalares. Só existe participação nas internações psiquiátricas, em que é cobrada uma co-participação de $50 \%$ do total das despesas. Constata-se que, neste caso, a existência de risco moral deve ser mais acentuada ou, ao menos, os incentivos para tal são maiores. Assim, os altos preços praticados podem estar servindo como mecanismo de compensação aos custos implicados pelo risco moral.

Outro fator importante é que os reajustes, principalmente após os 50 anos de idade, são elevados, sendo que a diferença entre a última faixa etária e a primeira é de quase seis vezes, dentro do limite estabelecido pela Lei dos planos e seguros de saúde. Como não é cobrada franquia alguma, a seguradora dispõe somente dos reajustes para tentar evitar a sobreutilização dos serviços aos usuários que adquirem este tipo de contrato de seguro.

Um fato que se destaca, comparando-se com outros casos, é que o prazo de carência para internações hospitalares é de seis meses, enquanto que para consultas é de quinze dias. Isto pode refletir uma demanda considerável por internações. Como as internações são mais caras do que as consultas médicas, foi imposto um prazo maior para a primeira.

As doenças e lesões preexistentes são tratadas da mesma forma que nas Cooperativas Médicas. Ou seja, em verificando-se a existência da doença, ou o consumidor paga agravo para estar coberto desde o início da vigência do seguro, ou então ele só terá a cobertura após dois anos da assinatura do contrato.

Verifica-se, no caso da Operadora 2, que o problema de risco moral pode estar presente neste tipo de seguro. Esta afirmação torna-se mais clara devido ao valor do prêmio de seguro cobrado, que equivale ao preço do plano oferecido pela Operadora 1 (no caso em que não existe co-participação). 
A Operadora 3, que faz parte da Associação Brasileira de Medicina de Grupo, só oferece contratos empresariais. O contrato a ser analisado constitui-se num plano ambulatorial e hospitalar sem obstetrícia. O funcionário da empresa que contratou a operadora tem a mensalidade do plano descontada na sua folha de pagamento. Atualmente, o valor cobrado pelo usuário de até 49 anos é o mesmo, independente da faixa etária. Após esta idade, até 59 anos, o valor é duplicado. Aos 60 anos, a taxa mensal também é duplicada. E, a partir dos 70 anos, é feito um reajuste de $2 \%$ a cada aniversário. Não é cobrado valor algum como taxa de co-participação. A maior parte do atendimento prestado por essa operadora é feito através de uma rede própria de estabelecimentos.

Esta situação caracteriza-se por induzir a uma grande incidência do problema de risco moral, por vários aspectos. Primeiro, por ser um contrato de um plano empresarial, o controle específico de cada usuário quanto à utilização dos serviços médicos e hospitalares torna-se prejudicado e menos visivel. Segundo, também pelo fato de ser um plano empresarial, o valor cobrado mensalmente costuma ser menor do que em planos individuais, justamente porque a operadora acaba fazendo um compartilhamento de risco entre os diversos associados de uma mesma empresa. Terceiro, não há cobrança de uma co-participação, juntamente com uma taxa mensal que não é tão elevada.

Neste contrato analisado, dois fatos interessantes estão relacionados ao número de associados, à carência e a doenças e lesões preexistentes. Se o número de associados do plano de uma empresa for menor do que cinqüenta, então existirá carência de dois meses para consultas e exames simples e de seis meses para exames especiais e internações hospitalares. Além disso, neste caso, as regras para doenças e lesões preexistentes serão aquelas mesmas citadas no caso das outras operadoras.

Entretanto, se o número de associados de uma empresa for maior do que cinqüenta, então não existirá período de carência seja qual for o procedimento necessário dentro da cobertura prevista. Também, nessa situação, será coberta qualquer tipo de lesão ou doença preexistente durante todo o tempo de vigência do contrato.

O que se pode depreender destas duas situações é que, com um número de associados maior que cinqüenta, a possibilidade de compartilhamento de risco é maior e não é necessário impor restri- 
ção alguma. Essa é uma das soluções propostas para se tentar diminuir a incidência do problema de risco moral. Já com menos do que cinqüenta associados é preciso impor certos limites, até para, indiretamente, tentar restringir ao máximo a entrada de empresas com poucos associados, pois neste caso a operadora terá que assumir mais riscos.

Finalizando a análise do contrato desta operadora, percebe-se que a possibilidade de compartilhar os riscos entre os diversos associados de uma empresa torna mais viável o não pagamento de uma taxa de co-participação, do que no caso de planos individuais ou familiares. Mesmo assim, dificilmente só com este tipo de mecanismo se consegue eliminar o problema de risco moral. Até porque continua sendo a operadora o agente que mais assume o risco, gerando conseqüências importantes e até mesmo decisivas para o futuro de muitas operadoras.

As duas próximas análises estão inseridas em um outro contexto. As entidades a serem analisadas são as chamadas entidades de autogestão. Cabe ressaltar, novamente, que estas empresas ou associações também estão sujeitas à Lei n. ${ }^{\circ}$ 9.656. Porém, os casos, apresentados a seguir, são de entidades que optaram por não realizar a adaptação de seus contratos à nova legislação. Dessa forma, elas não estão obrigadas a seguir a maioria das regras que foram estabelecidas. É interessante analisar estes dois casos, justamente para se verificar qual a conduta que era (e continua sendo) tomada pelas empresas antes da Lei n. ${ }^{\circ} 9.656$ entrar em vigor.

O quarto contrato analisado será o da Associação 4, a qual faz parte do CIEFAS (Comitê de Integração de Entidades Fechadas de Assistência à Saúde). Os integrantes do CIEFAS são basicamente associações de funcionários de órgãos públicos, que fornecem assistência médica e hospitalar para seus associados. A contribuição para este tipo de contrato é feita da seguinte forma: além das contribuições da entidade mantenedora e das fundadoras, cada empregado contribui com $1,654 \%$ sobre a base de contribuição ${ }^{14}$, mais $0,39 \%$ por cada dependente direto.

${ }^{14}$ A base de contribuição é definida como o somatório das parcelas do ordenado, gratificação por tempo de serviço, comissāo de cargo e a gratificação natalina, percebida por cada empregado. 
Neste contrato em análise, verifica-se a existência de vários mecanismos que pretendem combater o problema de risco moral. Primeiramente, como o contrato não foi adaptado à nova legislação, são impostos limites tanto para consultas médicas bem como para as internações hospitalares. De acordo com os limites estabelecidos especificamente para as consultas, também variam os percentuais de co-participação. Os percentuais e limites estabelecidos para as consultas médicas são os seguintes: será cobrado 30\% do valor total dos procedimentos caso o usuário faça no máximo 12 consultas por ano; $50 \%$ nas consultas quando estas forem mais que 12 ao ano e menor que 24; e se o beneficiário consultar mais do que 24 vezes num ano, será cobrado $100 \%$ do valor das consultas.

Com relação aos exames, seja de diagnóstico ou de tratamento, o percentual de co-participação é de 30\%. Quanto às internações, estabelece-se um limite de 60 dias por ano, corridos ou intercalados. As taxas de co-participação, neste caso, variam conforme uma classificação que é feita de acordo com a categoria do hospital, a qual depende da tabela de preços adotada por este. As taxas vão de $7,5 \%$ para hospitais de categoria $\mathrm{A}$, até $1,5 \%$ para os de categoria $\mathrm{E}$. Além disso, ainda é cobrada uma taxa de $10 \%$ sobre os serviços profissionais em hospital, como, por exemplo, anestesistas, obstetras, etc.

Quanto aos períodos de carência, são estabelecidas algumas diferenças conforme a data de inscrição. Se o beneficiário se inscrever no plano até trinta dias da data que adquire condição para tal, seus prazos de carência serão menores: trinta dias para consultas e exames que não necessitem de autorização prévia, já exames complexos e internações têm carência de quatro meses. Entretanto, caso o beneficiário se inscreva após os 30 dias, os prazos de carência sofrem alteraçōes: a carência para consultas e exames mais simples será de 2 meses, e de 8 meses para internações e exames mais complexos.

O contrato analisado, mesmo sendo de uma associação, a qual poderia fazer um melhor compartilhamento de risco, verifica-se que existe uma preocupação muito grande com relação à possibilidade de sobreutilização dos serviços prestados. Sendo o caso, dentre os cinco analisados, aquele em que o consumidor é mais sobrecarregado, tanto em termos financeiros quanto no que se refere aos limites para consultas e internações hospitalares.

A última análise de contrato a ser feita é a da Associação 5, que pertence à ABRASPE (Associação Brasileira das Autogestões em 
Saúde Patrocinadas pelas Empresas). O contrato estabelece tanto a contribuição por parte do empregador quanto por parte do empregado. Este último contribui com um percentual do seu rendimento mensal, que fica em torno de $6 \%$. Em média, a contribuição de empregador e empregado se equivalem. Não existe qualquer reajuste ou alteração nos preços em função da idade dos usuários.

Além disso, cobra-se percentual de co-participação e, da mesma forma como no contrato da outra associação, também se impõem limites ao número de consultas por mês. Só é permitido consultar uma vez a cada trinta dias e é cobrado $30 \%$ do valor de uma consulta. Para procedimentos ambulatoriais que custem mais de RS 190,00 , a taxa de co-participação é de $15 \%$. No caso de internações hospitalares, não existe taxa de co-participação, a não ser que o usuário precise realizar exames. Neste caso, ele irá pagar $\mathrm{R} \$ 10,00 \mathrm{a}$ cada $\mathrm{R} \$ 100,00$ gastos com os serviços.

Nota-se que o contrato desta associação possui pontos em que se percebe uma maior preocupação com a não racionalização dos serviços médicos e hospitalares, do que no caso anteriormente analisado. O limite de uma consulta a cada trinta dias também é bastante rígido e claramente é um mecanismo utilizado para combater o problema de risco moral, já que, por meio, dele se pode perceber a quantidade de serviços que está sendo demandada.

Quanto às carências, são exigidos noventa dias após a data de inscrição para que seja possível utilizar os serviços disponíveis. Exceto no caso de partos em que a carência, na grande maioria dos planos, é maior que 270 dias. O prazo de noventa dias pode ser considerado alto, principalmente no que se refere a consultas e exames. Mas esta é uma forma de prolongar a proteçāo contra possíveis gastos futuros e, conseqüentemente, de proteção contra a sobreutilização dos serviços, ou seja, contra o problema do risco moral, num instante imediato à inscrição no plano.

A análise desses cinco contratos permite se verificar a aplicação das principais soluções que foram propostas para o problema de risco moral como o percentual de co-participação e o compartilhamento de risco. Mesmo assim, observa-se que, no caso dos contratos coletivos, a possibilidade de incidência de risco moral é maior, já que tanto os custos dos próprios planos quanto os percentuais de co-participação são menores, o que favorece uma maior utilização dos serviços médicos e hospitalares. 
As empresas, que devem obedecer à Lei n. ${ }^{\circ}$ 9.656, estão utilizando os mecanismos de co-participação como forma de proteção, a fim de desincentivar o uso desnecessário dos serviços fornecidos. Conforme a análise feita, outro mecanismo que vem sendo utilizado é o aumento do prazo das carências, como forma de prolongar o tempo que o consumidor não pode se utilizar de serviço algum, período no qual a operadora acumula suas reservas para os gastos que aparecerão futuramente.

Já aqueles contratos analisados das entidades que não precisam se comportar de acordo com a Lei dos Planos e Seguros de Saúde utilizam-se, além dos mecanismos já citados, de limitação de consultas, exames, e internações. Este tipo de imposição é mais eficiente, em termos de proteção contra o problema de risco moral, já que se estabelece uma regra, a qual não pode ser descumprida. Ao contrário, por exemplo, da co-participação, que é um percentual cobrado sobre o valor da consulta médica e que se o consumidor estiver disposto a pagar, ele o faz. Inclusive porque, por maior que seja a taxa de co-participação, o usuário vai estar pagando menos do que se não possuísse um plano de saúde e tivesse que arcar com todas as despesas.

Então, como pode ser percebido pela análise dos contratos, cada operadora (ou associação) tem se utilizado dos meios legalmente possiveis para tentar amenizar o problema de sobreutilização dos serviços médicos e hospitalares, a fim de que consigam continuar prestando a assistência à saúde a todos os seus usuários. Entretanto, com os procedimentos adotados pelas operadoras, o ônus para os consumidores acaba aumentando, seja por meio de taxas de copagamento ou através de limites para consultas, cada vez que a operadora os utiliza para tentar diminuir o problema de risco moral, acaba onerando o consumidor. Em outras palavras, o resultado é ineficiente, em algum sentido, e isto ocorre porque há falha de informação. Entretanto, esse é um arranjo institucional tipo second best, pois a alternativa de não existência de assistência médica suplementar, além de não evitar o problema de risco moral, traria piora do bem-estar para toda a sociedade. 


\section{Considerações finais}

Este trabalho procurou evidenciar os principais mecanismos que estão sendo utilizados pelas operadoras de planos e seguros de saúde, a fim de se evitar o problema de risco moral, e de que forma os consumidores são atingidos por isso. Procurou-se mostrar as principais mudanças na conduta das operadoras após a regulamentação ocorrida neste setor, e de que maneira isso acabou acarretando em mais, ou menos, incentivos à sobreutilização dos serviços médicos e hospitalares prestados.

Primeiramente, foram apresentadas algumas abordagens teóricas sobre o problema de risco moral no mercado de seguros. Este levantamento foi importante por fornecer os fundamentos teóricos necessários para a análise realizada posteriormente, na medida em que mostrou algumas soluçōes para as situações de risco moral. Conforme a análise feita, as principais idéias dizem respeito ao compartilhamento do risco assumido, que deve ser feito entre seguradora e consumidor, à exigência do pagamento de co-participações ou franquias ou, até mesmo, à limitação de consultas e internações hospitalares.

Como foi visto, a literatura sobre risco moral, no que se refere a esta questão dos instrumentos que podem ser utilizados para diminuí-lo, é mais homogênea e não se encontram muitas discordâncias. Contudo, a agenda de pesquisa recente sobre este assunto aborda novas questões. Nyman (1999) analisa o estudo desenvolvido por Pauly (1968), e procura acrescentar que a perda de bem-estar, ocasionada pelo problema de risco moral no mercado de seguros, devese não somente ao efeito-preço, mas também ao efeito-renda. Segundo o autor, é necessário se considerar a existência do efeito-renda, nesta perda, pois foi verificado que ocorre um aumento no consumo de seguro, quando há um aumento na renda do consumidor. Este efeito se dá através de uma transferência de renda entre aquele consumidor que tem uma probabilidade de adoecer pequena, para aquele que possui uma alta probabilidade. Assim, quanto menor a probabilidade de doença, maiores serão as transferências dos indivíduos saudáveis para aqueles que incorrem em maior risco.

Outra questão interessante de ser trabalhada são os efeitos do risco moral em um período de tempo maior. Por exemplo, Holmström (1979) afirma que o problema do risco moral pode ser amenizado 
com o passar do tempo, pois os efeitos da incerteza tendem a diminuir e os desvios no comportamento do indivíduo vão sendo revelados com maior precisão.

Estes, então, são alguns pontos abordados mais recentemente, que justificam por que ainda existe um vasto campo de pesquisa nesta área de assimetria de informação, sendo que, como se pode perceber, os trabalhos estão buscando detectar, cada vez com maior exatidão, quais os reais ganhos e perdas quanto existe o problema do risco moral e de que forma é possivel amenizar sua incidência.

Quanto à assistência suplementar à saúde, pode-se destacar que devido a sua forte expansão, tornou-se necessária uma regulamentação própria para esse setor. Tal processo ainda não se encerrou e seus efeitos serão conhecidos daqui a alguns anos, pois se implementaram medidas que alteraram profundamente os procedimentos realizados até então.

Por fim, na última seção, se observou, por meio dos contratos analisados, que as operadoras de planos e seguros de saúde estão utilizando-se de mecanismos possíveis de compartilhamento de ris$\mathrm{co}$, visando diminuir o problema de risco moral. Seja por meio da cobrança de co-pagamentos, seja estendendo o prazo de carência, limitando o número de consultas e internações hospitalares, etc. $\mathrm{O}$ que se percebe é que os mecanismos existentes estão sendo utilizados até o limite legal, para que se possa induzir uma racionalização no uso dos serviços médicos e hospitalares. Entretanto, com a utilização desses mecanismos, os consumidores estão sendo onerados cada vez mais e por isso, em alguns casos, acabam tendo que abandonar seus planos de saúde.

Dos cinco contratos que foram aqui estudados, as operadoras que estão mais expostas ao problema do risco moral, ao menos na relação com o consumidor, são as entidades de autogestão, que costumam ter mensalidades mais baratas, e que, mesmo cobrando um percentual de co-participação, ainda estão suscetiveis ao problema da sobreutilização dos serviços. Provavelmente, por isso, é que resolveram por não adaptar seus contratos, ao menos nos dois casos analisados, para que possam utilizar outros mecanismos, como a limitação de consultas e internações, que, se estivessem sob a vigência da Lei, seriam consideradas práticas ilegais.

Outro fato, que se pode destacar, é que o problema do risco moral, que surge na relação com alguns prestadores de serviços (clí- 
nicas, hospitais, etc.), não possui um mecanismo eficiente de controle que evite as fraudes e que incentive a racionalização dos serviços fornecidos. Da mesma forma, é necessário que o risco seja compartilhado entre as duas partes, ou seja, que hospitais, clínicas, também sejam responsáveis pelas despesas de um paciente. Somente assim, é possível diminuir, de alguma forma, os incentivos negativos que existem hoje e que acabam gerando o problema de risco moral. Como se percebe, um dos desafios que se tem no mercado brasileiro de assistência médica suplementar é o de se conseguir que o atendimento seja adequado, sem a imposição de restrições que infrinjam a lei, mas, ao mesmo tempo, sem sobrecarregar um dos agentes, seja quem for, quanto aos riscos que precisam ser assumidos na assistência médica.

\section{Referências bibliogróficas}

ALMEIDA, C. O mercado privado de serviços de saúde no Brasil: panorama atuale tendências da assistência médica suplementar. IPEA, 1998. Texto para Discussão, n. 599.

ANDRADE, M. V. A Regulamentação dos Contratos de Seguro Saúde no Brasil: gerando seleção adversa. In: ANDRADE, M. V. Ensaios em Economia da Saúde. Rio de Janeiro: EPGE-FGV, 2000.

ANDRADE, M. V., LISBOA, M. B. Economia da Saúde no Brasil In: Microeconomia e Sociedade no Brasil. 1 ed. Rio de Janeiro : Contra Capa, 2001, p.285-332.

Sistema privado de seguro-saúde: lições do caso americano. Revista Brasileira de Economia, Rio de Janeiro, n. 54(1), p. 5-36, jan./mar. 2000.

ARNOTT, R 8 STIGLITZ, J. Equilibrium in Competitive Insurance Markets with Moral Hazard. NBER Working Paper ${ }^{\circ}$ 3588, jan, 1991.

BRASIL. Ministério da Saúde. Agência Nacional de Saúde. Regulação dos planos privados de assistência à saúde pela ANS: avaliação, perspectivas e interface SUSSaúde Suplementar. Brasilia: 2001.30p. Disponível em http:/www.ans.saude.gov.br Acesso em 5/mar/2002.

CUTLER, D. M; ZECKHAUSER, R. J. The anatomy of health insurance. In: CULYER, a 3 NEWHOUSE, J. Handbook of health economics. Elsevier, v.1, p. 564-643, 2000

HOLMSTRÖM, B. Moral Hazard and Observability. Bell Journal of Economics, v.10, p. 74-91, 1979.

KATZ, M. L. ; ROSEN, H. S. Microeconomics. Homewood : Irwin, 1991. p. 595-636. 
NYMANN, J. A. The Economics of Moral Hazard Revisited. Journal of Health Economics. Elsevier, 1999. Vol. 18(6), p. 811-824.

PAULY, M. V. The economics of moral hazard: comment. The American Economic Review. v. 58, p. 531-537, jun, 1968.

PRESCOTT, E. A Primer on Moral Hazard Models. Federal Reserve Bank of Richmond Economic Quartely. v. 85(1), p. 47-77, winter, 1999.

SALANIÉ, B. The Economics of Contracts: a primer. Cambridge, MIT Press, 1997.

SHAVELL, S. (1979). On Moral Hazard and Insurance. Quartely Journal of Economics. v. 93, p. 541-562. 